\title{
Museos españoles en Facebook: análisis de su comunicación como museos sociales
}

\section{Spanish museums on Facebook: analysis of their communication as social museums}

\author{
Mas Iglesias, J. M. ${ }^{1}$ \\ Recibido: 14-05-2018 - Aceptado: 20-06-2018 \\ DOI: https://doi.org/10.26441/RC17.2-2018-A8
}

\begin{abstract}
RESUMEN: En los últimos años, la irrupción de las tecnologías digitales obliga a los museos no sólo a tratar de aprovechar estas nuevas posibilidades sino también a procurar optimizarlas para fortalecer la consecución de un museo que sea más social, participativo y colaborativo, en línea con lo que están haciendo también otras instituciones culturales. En este contexto, las redes sociales en general y Facebook en particular pueden ofrecer muchas oportunidades. El objetivo de este artículo es analizar la comunicación de los museos españoles en Facebook para evaluar hasta qué punto la están utilizando en este sentido. Para ello hemos llevado a cabo un análisis de contenido de los mensajes publicados durante 6 meses por los 10 museos españoles con más seguidores en Facebook. Los resultados confirman que su uso promocional prevalece en cantidad y variedad sobre otras modalidades más orientadas a crear comunidad, como cabría esperar de un museo verdaderamente social.
\end{abstract}

Palabras clave: museos; museo social digital; Facebook; España; comunicación corporativa; engagement.

ABSTRACT: In recent years, the irruption of digital technologies forces museums not only to try to take advantage of these new possibilities but also to seek to optimize them to strengthen the achievement of a more social, participatory and collaborative museum, in line with what other cultural institutions are doing as well. In this context, social networks in general -and Facebook in particular- can offer many opportunities. The aim of this paper is to analyze the communication of Spanish museums in this service in order to assess the extent to which they are using it in this sense. To do so, we have carried out a content analysis of the messages posted during 6 months by the 10 most followed Spanish museums on Facebook. Results confirm that its promotional use prevails, both in quantity and variety, over other modalities more aimed at creating community, as might be expected from a social museum.

Keywords: museums; digital social museum; Facebook; Spain; corporate communication; engagement.

\footnotetext{
1 José Manuel Mas Iglesias es Master en Marketing por la Universidad Rey Juan Carlos de Madrid, Honours Degree in Business Administration Humberside University (United Kingdom) y Doctorando en la Universidad Carlos III de Madrid. Se desempeña como Profesor de las asignaturas Ecosistema Digital, Marketing Digital y Dirección Estratégica en ESIC Business and Marketing School (España). josemanuel.mas@esic.edu, https://orcid.org/0000-0003-2931-1235
} 


\section{Introducción}

En los últimos años, la irrupción de las tecnologías digitales sociales obliga a los museos no sólo a tratar de aprovechar este nuevo contexto sino también a procurar optimizar sus posibilidades para fortalecer el logro de un museo que sea más social, participativo y colaborativo, en línea con lo que está ocurriendo también con otras instituciones culturales y consecuente con una nueva museología que apuesta por acercarse a la sociedad (Cordón \& González González, 2016). De este modo, la noción de museo social, ya presente desde la segunda mitad del siglo XX, y materializado incluso en movimientos vanguardistas de artistas que buscaban sacar el arte a la calle en los años 60 (Mateos, 2012), se puede ver potenciada por este escenario hasta el punto de dar paso a una nueva versión: la del museo social digital. Dentro de este contexto, las redes sociales en general -y Facebook en particularofrecen un gran potencial (Viñaras \& Caerols, 2016).

El objetivo de este artículo es analizar la comunicación de los museos españoles en Facebook para evaluar hasta qué punto la están utilizando en este sentido. Para ello hemos elaborado un análisis de contenido de los mensajes publicados durante 6 meses por los 10 museos españoles con más seguidores en Facebook. Examinamos su contenido pero también su forma. En la primera parte proponemos una caracterización del museo social digital frente al museo social con la idea de iluminar mejor el marco teórico en el que ubicamos nuestro estudio.

\section{Del museo tradicional al museo so- cial digital}

Siguiendo a Gómez Vílchez (2012), la historia de los museos se puede entender en gran parte como una historia social: "Del coleccionismo privado hasta el origen de los primeros museos públicos se ha recorrido un extenso camino en el que los museos se han ido haciendo cada vez más cercanos, abiertos y sociales" (Gómez Vílchez, 2012: 1).

La noción de museo social como desafío y utopía de referencia se remonta a la segunda mitad del siglo XX, cuando emergen una serie de conceptos que colisionan con las formas más tradicionales de concebir las funciones y contenidos que los museos habían tenido a lo largo de buena parte de su historia (la conservación, el edificio, los objetos, el público...). Se trata de una nueva museología que tiene a su principal representante en Georges H. Rivière, Director del Consejo Internacional de Museos ICOM. La teoría propone la necesidad de que el museo se abra y renueve, tanto en sus modos de producción de conocimientos como en sus modalidades de exposición y socialización.

Este impulso se materializa en mayo de 1972 en la Mesa Redonda Internacional de Chile titulada "Desarrollo y el papel de los museos en el mundo contemporáneo". A juicio de De Varine-Bohan (1973, 1978, 1979, 1989 y 1993), estas consideraciones abren un nuevo campo de posibilidades a las instituciones museísticas, entre ellas, la aceptación de su papel social y el reto de comprometerse al desarrollo y servicio de la sociedad. 
Con este punto de partida, el museo da paso a una nueva etapa que se centra en los criterios de utilidad social y que gira la atención hacia el público, ya no como simple visitante, sino como participante del diálogo y epicentro de las interacciones (Desvallées y Mairesse, 2010).

Según esta corriente innovadora, los museos tendrían la responsabilidad de promover y fomentar activamente el cambio social al expandir la experiencia de los visitantes más allá del espacio físico. Los espacios museísticos salen de sus muros y se transforman, de esta forma, en una plataforma de creación y debate en la que es preciso conocer las opiniones, necesidades, inquietudes y características de su público. Se trata de un concepto de museo que se abre a la sociedad, contemplándola como un agente activo.

Desde una perspectiva más concreta, el museo social propone varias transformaciones importantes respecto a lo que, por contraste, podríamos denominar museo tradicional. En su tesis doctoral, Llerena (2016), que dedica una parte importante a examinar esta transición, sistematiza las principales diferencias en la siguiente tabla comparativa:

Tabla 1. Análisis comparativo entre el museo tradicional y el museo social

\begin{tabular}{|l|l|l|}
\hline \multicolumn{1}{|c|}{ Características } & \multicolumn{1}{|c|}{ Museo tradicional } & \multicolumn{1}{c|}{ Museo social } \\
\hline $\begin{array}{l}\text { Los museos son } \\
\text { espacios para: }\end{array}$ & Expertos. Son excluyentes & $\begin{array}{l}\text { Todos. El museo participativo se define } \\
\text { como un espacio en el que los visitantes } \\
\text { contribuyen a la institución con ideas y } \\
\text { aportaciones, y donde se fomenta el } \\
\text { diálogo y la socialización. Se les brinda } \\
\text { la oportunidad de crear y conectar con } \\
\text { personas que comparten los mismos } \\
\text { intereses }\end{array}$ \\
\hline $\begin{array}{l}\text { La exposición se } \\
\text { deriva de: }\end{array}$ & $\begin{array}{l}\text { La autoridad de los } \\
\text { conservadores y científicos } \\
\text { de forma exclusiva }\end{array}$ & $\begin{array}{l}\text { Un proceso colaborativo con los } \\
\text { visitantes a través de estudios de } \\
\text { público }\end{array}$ \\
\hline $\begin{array}{l}\text { El foco de la } \\
\text { exposición se pone } \\
\text { en: }\end{array}$ & $\begin{array}{l}\text { La presentación de los } \\
\text { objetos y apenas se tiene } \\
\text { en cuenta la recepción }\end{array}$ & $\begin{array}{l}\text { El compromiso y la experiencia del } \\
\text { público, que resultan fundamentales }\end{array}$ \\
\hline $\begin{array}{l}\text { El centro de la } \\
\text { actividad lo constituye: }\end{array}$ & Colección e investigación & Visitantes \\
\hline $\begin{array}{l}\text { La visión que se tiene } \\
\text { de la comunicación } \\
\text { es: }\end{array}$ & $\begin{array}{l}\text { Transmisiva: los objetos } \\
\text { transmiten información que } \\
\text { el visitante debe adquirir }\end{array}$ & $\begin{array}{l}\text { Cultural: existe una interacción constan- } \\
\text { te entre objeto y sujeto }\end{array}$ \\
\hline El conocimiento es: & $\begin{array}{l}\text { Único y cerrado. El museo } \\
\text { lo reelabora y lo presenta } \\
\text { sin posibilidad de interpre- } \\
\text { tación }\end{array}$ & $\begin{array}{l}\text { Múltiple, abierto y se presenta de } \\
\text { manera que admite muchas interpreta- } \\
\text { ciones }\end{array}$ \\
\hline $\begin{array}{l}\text { El conocimiento se } \\
\text { deriva de: }\end{array}$ & Forma externa al sujeto & $\begin{array}{l}\text { El sujeto, que interactúa de forma activa } \\
\text { y participativa }\end{array}$ \\
\hline
\end{tabular}




\begin{tabular}{|c|c|c|}
\hline $\begin{array}{l}\text { El público se concibe } \\
\text { como: }\end{array}$ & $\begin{array}{l}\text { Receptor de un conoci- } \\
\text { miento previamente } \\
\text { elaborado por el museo }\end{array}$ & $\begin{array}{l}\text { Constructor de aprendizajes, experien- } \\
\text { cias, conocimientos y vivencias }\end{array}$ \\
\hline $\begin{array}{l}\text { El docente es visto } \\
\text { como: }\end{array}$ & $\begin{array}{l}\text { Un simple transmisor y } \\
\text { reproductor del conocimien- } \\
\text { to que posee el museo }\end{array}$ & $\begin{array}{l}\text { Un facilitador y mediador que participa } \\
\text { de la construcción del conocimiento que } \\
\text { presenta el museo }\end{array}$ \\
\hline $\begin{array}{l}\text { La visión que se tiene } \\
\text { del aprendizaje es: }\end{array}$ & $\begin{array}{l}\text { Positivista y conductista. El } \\
\text { aprendizaje es acumulado } \\
\text { y se absorbe mediante la } \\
\text { suma de la información } \\
\text { transmitida por un agente } \\
\text { externo. El público es un } \\
\text { mero consumidor pasivo }\end{array}$ & $\begin{array}{l}\text { Constructivista. El aprendizaje es activo, } \\
\text { implica una reestructuración de los } \\
\text { esquemas mentales de quien se } \\
\text { aprende. El aprendizaje es participativo } \\
\text { y dialógico. El público es parte activa de } \\
\text { un espacio de encuentro social y de } \\
\text { intercambio de conocimiento }\end{array}$ \\
\hline $\begin{array}{l}\text { La evaluación se } \\
\text { hace a través de: }\end{array}$ & $\begin{array}{l}\text { No existe este espacio de } \\
\text { reflexión }\end{array}$ & $\begin{array}{l}\text { Identifica y desarrolla audiencias } \\
\text { potenciales, se comunica con las } \\
\text { comunidades y conoce cómo los } \\
\text { públicos experimentan el museo y la } \\
\text { percepción que tienen de él. Se centra } \\
\text { en la conducta de los participantes y en } \\
\text { el impacto de las acciones, es decir, en } \\
\text { lo que hacen y en lo que sucede como } \\
\text { resultado de esa experiencia }\end{array}$ \\
\hline $\begin{array}{l}\text { La comunicación/ } \\
\text { conversación es: }\end{array}$ & $\begin{array}{l}\text { Proveer una información } \\
\text { unidireccional para la mera } \\
\text { difusión y autopromoción } \\
\text { de su trabajo }\end{array}$ & $\begin{array}{l}\text { Bidireccional: entendiendo estos } \\
\text { espacios como lugares de interacción }\end{array}$ \\
\hline $\begin{array}{l}\text { Los servicios de } \\
\text { comunicación e } \\
\text { interpretación } \\
\text { museológica: }\end{array}$ & $\begin{array}{l}\text { Restringidos al interior del } \\
\text { espacio del museo }\end{array}$ & Se encuentran en todas partes \\
\hline
\end{tabular}

Fuente: Llerena (2016) a partir de las propuestas de Keene (2004), Gómez Vílchez (2010) y Miranda (2013)

En los últimos años son varias las tecnologías que permiten profundizar en esta idea de museo social. Siguiendo a Cano, Vázquez y Celaya:

La tecnología está resultando ser una fantástica herramienta para responder a las necesidades que los asiduos al museo tienen y, cómo no, para ampliar los públicos. Los museos tienen (o deben tener) como uno de sus objetivos principales dar cabida al mayor número de voces posible. Las nuevas páginas web, las redes sociales, la digitalización de documentos (...) y otras muchas estrategias digitales que se están adoptando han conseguido que el museo traspase sus muros como nunca antes, haciéndolo accesible a cualquiera con una conexión a Internet, sea cual sea el lugar donde se encuentre (Cano, Vázquez y Celaya, 2015: 220).

Entre estas tecnologías podemos mencionar también con Castilla (2012) los dispositivos móviles y smartphones, la realidad virtual y realidad aumentada, las herramientas táctiles, los elementos 
audiovisuales escenográficos capaces de favorecer la sensación de inmersión y las pantallas 3D o las pantallas de niebla y proyección esférica. La interacción de éstas y otras tecnologías permite profundizar en la consecución de un museo verdaderamente social y abre también la puerta a la idea de un museo social digital. A falta de una denominación previa, definimos este museo social digital como un:

...espacio museístico que sabe aprovechar las oportunidades que ofrecen las tecnologías digitales para profundizar en la consecución de un museo que sea verdaderamente cercano, abierto y social, promocionando su actividad a través de nuevos cauces atractivos pero tratando también de crear comunidad con su público actual y potencial (Mas, 2018).

De esta forma, el museo social digital sería aquél que procura sacar el máximo partido a estas tecnologías para favorecer la accesibilidad al conocimiento expuesto, ampliar la exposición al público objetivo, personalizar la interacción adaptándola a la de su público y, eventualmente, enriquecer la experiencia del visitante. A su vez esto favorece la imagen del museo como una plataforma que conecta audiencias, contenidos y experiencias (Mas, 2018). Completamos la caracterización con el siguiente análisis comparativo entre el museo social y su versión digital:

Tabla 2. Análisis comparativo entre el museo social y el museo social digital

\begin{tabular}{|l|l|l|}
\hline Características & \multicolumn{1}{|c|}{ Museo social } & \multicolumn{1}{|c|}{ Museo social digital } \\
\hline $\begin{array}{l}\text { Los museos son } \\
\text { espacios para: }\end{array}$ & $\begin{array}{l}\text { Todos. El museo participativo se } \\
\text { define como un espacio en el } \\
\text { que los visitantes contribuyen a } \\
\text { la institución con ideas y } \\
\text { aportaciones, y donde se } \\
\text { fomenta el diálogo y la } \\
\text { socialización. Se les brinda la } \\
\text { oportunidad de crear y conectar } \\
\text { con personas que comparten los } \\
\text { mismos intereses. }\end{array}$ & $\begin{array}{l}\text { Todos. Las tecnologías digitales } \\
\text { potencian la interacción del visitante } \\
\text { con el museo y la interacción entre los } \\
\text { propios visitantes, incluso de forma } \\
\text { autónoma a través de sus propios } \\
\text { dispositivos móviles. Estos dispositivos } \\
\text { permiten personalizar la experiencia y } \\
\text { enriquecer asíla visita, adaptándola a } \\
\text { cada uno. } \\
\text { Los dispositivos digitales fomentan por } \\
\text { tanto la conectividad, la creatividad y la } \\
\text { participación del visitante }\end{array}$ \\
\hline $\begin{array}{l}\text { La exposición } \\
\text { se deriva de: }\end{array}$ & $\begin{array}{l}\text { Un proceso colaborativo con los } \\
\text { visitantes a través de estudios de } \\
\text { público. }\end{array}$ & $\begin{array}{l}\text { La tecnología digital permite una } \\
\text { trazabilidad de la experiencia del } \\
\text { visitante, que arroja, incluso en tiempo } \\
\text { real, datos sobre gustos, interacciones } \\
\text { preguntas, que pueden mejorar la } \\
\text { propia exposición en tiempo real } \\
\text { La participación del visitante en la } \\
\text { generación de la exposición se } \\
\text { convierte en una realidad. }\end{array}$ \\
\hline
\end{tabular}




\begin{tabular}{|c|c|c|}
\hline $\begin{array}{l}\text { El foco de la } \\
\text { exposición se } \\
\text { pone en: }\end{array}$ & $\begin{array}{l}\text { El compromiso y la experiencia del } \\
\text { público, que resultan } \\
\text { fundamentales. }\end{array}$ & $\begin{array}{l}\text { La interacción del visitante con la obra } \\
\text { expuesta, de forma adaptada y } \\
\text { personalizada. Evoluciona el concepto } \\
\text { de visitante como concepto global, a la } \\
\text { interacción que cada individuo hace en } \\
\text { cada visita. }\end{array}$ \\
\hline $\begin{array}{l}\text { El centro de la } \\
\text { actividad lo } \\
\text { constituye: }\end{array}$ & Visitantes & $\begin{array}{l}\text { Cada visitante como individuo único } \\
\text { (personalización y adaptación) }\end{array}$ \\
\hline $\begin{array}{l}\text { La visión que se } \\
\text { tiene de la } \\
\text { comunicación } \\
\text { es: }\end{array}$ & $\begin{array}{l}\text { Cultural: existe una interacción } \\
\text { constante entre objeto y sujeto }\end{array}$ & $\begin{array}{l}\text { Cultural y abierta a la comunidad: los } \\
\text { individuos interactúan alrededor de una } \\
\text { temática cultural propuesta por el museo. } \\
\text { Éste provee el contenido sobre el que se } \\
\text { basa la interrelación de los individuos }\end{array}$ \\
\hline $\begin{array}{l}\text { El conocimiento } \\
\text { es: }\end{array}$ & $\begin{array}{l}\text { Múltiple, abierto y se presenta de } \\
\text { manera que admite muchas } \\
\text { interpretaciones }\end{array}$ & $\begin{array}{l}\text { Adaptable a la experiencia que quiere } \\
\text { tener cada individuo }\end{array}$ \\
\hline $\begin{array}{l}\text { El conocimiento } \\
\text { se deriva de: }\end{array}$ & $\begin{array}{l}\text { El sujeto, que interactúa de forma } \\
\text { activa y participativa }\end{array}$ & $\begin{array}{l}\text { La comunidad en general y el individuo } \\
\text { de forma particular e individual }\end{array}$ \\
\hline $\begin{array}{l}\text { El público se } \\
\text { concibe como: }\end{array}$ & $\begin{array}{l}\text { Constructor de aprendizajes, } \\
\text { experiencias, conocimientos y } \\
\text { vivencias }\end{array}$ & $\begin{array}{l}\text { Consumidor de experiencias } \\
\text { individualizadas y protagonista de su } \\
\text { propia visita }\end{array}$ \\
\hline $\begin{array}{l}\text { El docente es } \\
\text { visto como: }\end{array}$ & $\begin{array}{l}\text { Un facilitador y mediador que } \\
\text { participa de la construcción del } \\
\text { conocimiento que presenta el museo }\end{array}$ & $\begin{array}{l}\text { Dinamizador de la comunidad que } \\
\text { acerca la experiencia al neófito }\end{array}$ \\
\hline $\begin{array}{l}\text { La visión que se } \\
\text { tiene del } \\
\text { aprendizaje es: }\end{array}$ & $\begin{array}{l}\text { Constructivista. El aprendizaje es } \\
\text { activo, implica una reestructuración } \\
\text { de los esquemas mentales de } \\
\text { quien se aprende. El aprendizaje } \\
\text { es participativo y dialógico. El } \\
\text { público es parte activa de un } \\
\text { espacio de encuentro social y de } \\
\text { intercambio de conocimiento } \\
\end{array}$ & $\begin{array}{l}\text { Personalizada a través de la experiencia } \\
\text { única que tiene cada visitante. A su vez } \\
\text { esta experiencia se basa en múltiples } \\
\text { estímulos, generados tanto por el museo } \\
\text { como por el resto de la comunidad }\end{array}$ \\
\hline $\begin{array}{l}\text { La evaluación se } \\
\text { hace a través de: }\end{array}$ & $\begin{array}{l}\text { Identifica y desarrolla audiencias } \\
\text { potenciales, se comunica con las } \\
\text { comunidades y conoce cómo los } \\
\text { públicos experimentan el museo y } \\
\text { la percepción que tienen de él. Se } \\
\text { centra en la conducta de los } \\
\text { participantes y en el impacto de } \\
\text { las acciones, es decir, en lo que } \\
\text { hacen y en lo que sucede como } \\
\text { resultado de esa experiencia }\end{array}$ & $\begin{array}{l}\text { Diferentes mecanismos interactivos que } \\
\text { permiten obtener una evaluación } \\
\text { individualizada y en tiempo real }\end{array}$ \\
\hline $\begin{array}{l}\text { La } \\
\text { comunicación/ } \\
\text { conversación es: }\end{array}$ & $\begin{array}{l}\text { Bidireccional: entendiendo estos } \\
\text { espacios como lugares de } \\
\text { interacción }\end{array}$ & Multidireccional: museo y comunidad \\
\hline $\begin{array}{l}\text { Los servicios de } \\
\text { comunicación e } \\
\text { interpretación } \\
\text { museológica: }\end{array}$ & Se encuentran en todas partes & $\begin{array}{l}\text { No tienen una ubicación espacio } \\
\text { temporal. Se puede acceder a ellos } \\
\text { desde cualquier lugar y en cualquier } \\
\text { momento }\end{array}$ \\
\hline
\end{tabular}




\section{Material y métodos}

En el contexto que acabamos de describir, el objetivo de este artículo es analizar la comunicación de los museos españoles en Facebook para ver hasta qué punto están utilizando esta red para profundizar en la consecución de un museo verdaderamente social. Para ello, partimos de tres hipótesis. En una primera observación de las cuentas en Facebook de algunos de los principales museos españoles, nos dimos cuenta de que éstos publicaban con cierta frecuencia, lo cual nos llevó a pensar que los museos habían normalizado el empleo de esta red. También en esta primera observación advertimos que las publicaciones solían estar enfocadas a visibilizar y promocionar su actividad, así como a educar o instruir a los seguidores sobre aspectos relativos al arte. Fueron estas consideraciones las que nos llevaron a formular la primera hipótesis, que planteamos en los siguientes términos:

HIPÓTESIS 1: Los museos españoles han normalizado el empleo de la red social Facebook, canal que utilizan sobre todo para visibilizar y promocionar su actividad y, en menor medida, para alfabetizar al público respecto al arte.

En una revisión más atenta, también advertimos que estos museos centraban su actividad sobre todo en publicar, y no tanto en conversar con los seguidores pese al potencial que esta red ofrece para ello (Moreno, 2014, 2015 y 2018). Fue esta observación la que nos llevó a proponer esta segunda hipótesis:

HIPÓTESIS 2: Salvo excepciones, los museos españoles más populares en Facebook apenas aprovechan esta red social para conversar con sus seguidores y crear comunidad

En esta revisión preliminar también nos dimos cuenta de que la mayoría de los posts incluían una o varias fotografías, pero resultaba difícil encontrar publicaciones en las que los museos aprovechasen otros elementos multimedia que ofrece Facebook para enriquecer la información puramente textual (Moreno, 2014, 2015 y 2018). Por ello, propusimos esta tercera hipótesis:

HIPÓTESIS 3: En cuanto al aprovechamiento del potencial multimedia que ofrece el servicio, los museos analizados recurren de manera prioritaria a las fotos aunque desaprovechan otras posibilidades de enriquecer sus mensajes.

Para comprobar hasta qué punto esto es así hemos llevado a cabo un análisis de contenido (Berelson, 1952; Bardin, 1991; Wimmer y Dominick, 2011) de la comunicación de 10 de los museos españoles con mayor número de fans en Facebook.

En cuanto a la unidad de análisis, optamos por escoger el post; es decir, cada una de las actualizaciones publicadas por estos museos. Examinamos su comunicación desde el punto de vista de su contenido pero también de su forma a partir de un código propio que tiene en cuenta la literatura sobre el tema y que incluye un total de 24 variables.

Desde una perspectiva más concreta, algunas de las variables que proponemos para operacionalizar el estudio de la primera hipótesis tienen que ver con el nivel de actividad de los museos en Facebook, el día de la semana en el que más publican, las horas del día a las que más lo hacen, las finalidades principales 
y secundarias tanto para el conjunto de la muestra como para cada uno de los museos analizados, la frecuencia con la que utilizan Facebook para promocionar su actividad o para alfabetizar a los seguidores respecto al arte.

Tabla 3. Diez museos españoles con mayor número de fans/seguidores en Facebook (febrero de 2017)

\begin{tabular}{|l|c|c|}
\hline Museos & Fans/seguidores & Ciudad en la que se encuentra \\
\hline Museo del Prado & 903.894 & Madrid \\
\hline Museo Reina Sofía & 352.687 & Madrid \\
\hline Museo Guggenheim & 236.467 & Bilbao \\
\hline Museo Picasso & 161.044 & Barcelona \\
\hline Museo Thyssen Bornemisza & 143.910 & Madrid \\
\hline MACBA & 78.057 & Bilbao \\
\hline Museo de Bellas Artes de Bilbao & 60.213 & Málaga \\
\hline CAC Málaga & 44.638 & Barcelona \\
\hline Museo Nacional de Arte de Cataluña & 39.140 & Madrid \\
\hline Museo del Traje de Madrid & 36.152 & \\
\hline
\end{tabular}

Fuente: Elaboración propia a partir de la información que proporciona Socialbakers²

En el caso de la segunda hipótesis, sobre el poco aprovechamiento que los museos españoles hacen del potencial que ofrece Facebook para crear comunidad, algunas de las variables que proponemos son la frecuencia con la que los museos interactúan con sus seguidores, refuerzan el contacto con ellos, solicitan su participación para recabar información, opinión o para que participen en juegos y concursos. En este apartado analizamos también la frecuencia con la que mencionan otras cuentas o enlazan a otras redes sociales en las que puedan tener un perfil como un modo complementario de seguir creando comunidad en estos otros espacios.
Con respecto a la tercera hipótesis, sobre lo poco que los museos españoles aprovechan el potencial multimedia que ofrece Facebook, las variables que proponemos incluyen la frecuencia con la que enlazan a fotos, audios, o vídeos así como la frecuencia con la que realizan transmisiones en vivo, incluyen hashtags o emoticonos.

Como decimos, la muestra está integrada por la actividad generada por los 10 museos mencionados a lo largo de 6 meses, durante un periodo de 8 , para evitar la presencia de algún factor que pudiese condicionar los resultados en un sentido u otro. En concreto, los meses que analizamos fueron: 
i) julio y agosto de 2016,

ii) octubre y noviembre de 2016, y

iii) enero y febrero de 2017.

Durante estos 6 meses, los 10 museos objeto de estudio publicaron un total de 2.336 actualizaciones. Tras codificar cada una de ellas en Excel a partir de un sistema de cuantificación nominal (Wimmer y Dominick, 2011: 167), exportamos los datos a SPSS (versión 23.0) con el propósito de extraer las frecuencias y análisis de contingencia y redactar así los resultados que ahora presentamos.

\section{Resultados}

Por razones de espacio, presentamos aquí sólo una selección de 10 de los hallazgos más destacados. Lo hacemos casi a modo de titulares. En algún caso completamos este apartado con capturas de pantalla para ilustrar mejor lo que dan de sí los datos:

\subsection{Los museos españoles han norma- lizado el uso de Facebook como canal habitual para su comunicación}

La actividad media para el conjunto de la muestra es de 38,8 publicaciones al mes, lo que supone una media de 1,3 publicaciones al día. El museo con mayor actividad es el Reina Sofía, con 452 publicaciones, un $20 \%$ del total de las publicaciones y una media de 2,5 posts al día. Le siguen el CAC de Málaga, con un $17 \%$ del total, y el Guggenheim de Bilbao con un 14\%. Los tres últimos puestos están ocupados por el MACBA, con un 6\% de publicaciones sobre el total de la muestra, el Museo del Traje de Madrid, con un $4 \%$ y el Museo Picasso de Barcelona, que sólo suma 74 de las 2.336 publicaciones analizadas. Esto supone una media diaria de 0,4 publicaciones para este museo. Los datos quedan reflejados en el siguiente histograma:

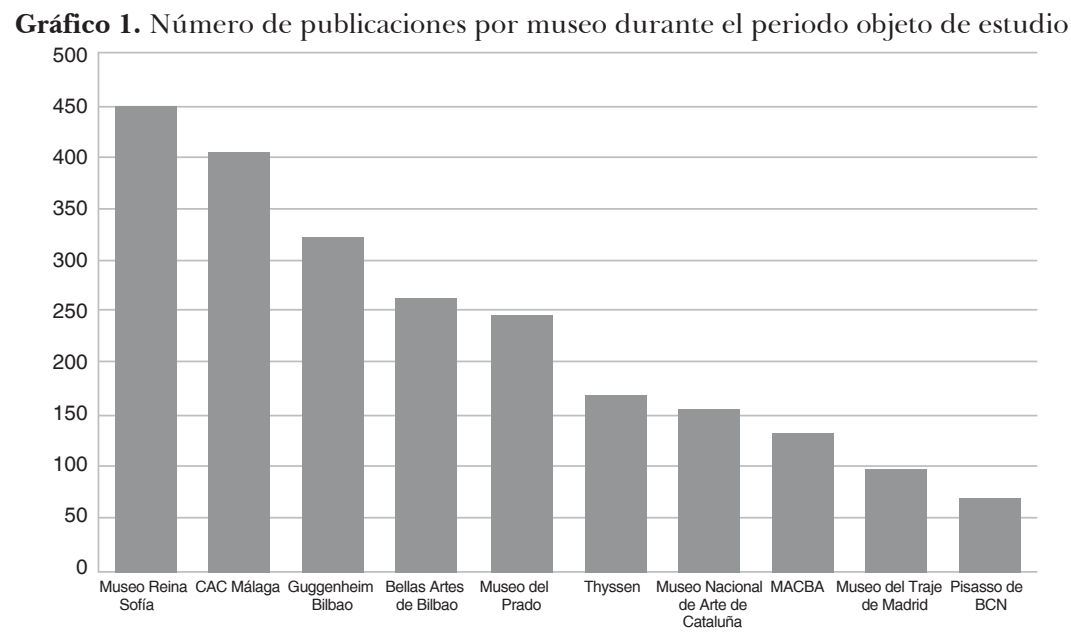

Fuente: Elaboración propia 
4.2. Promocionar su actividad es la finalidad principal de los museos españoles en Facebook

Tal como anticipábamos en la formulación de nuestra primera hipótesis, los resultados revelan que los museos seleccionados utilizan Facebook sobre todo para promocionar la actividad del museo (exposiciones, conferencias, seminarios, eventos, actividades, etc.). A esta finalidad se dirige un $73,8 \%$ del total de mensajes que publican los museos durante el periodo analizado. El siguiente uso es el de alfabetizar al público respecto al arte, propósito que, no obstante, se encuentra a bastante distancia del anterior. Así lo podemos apreciar en el histograma (gráfico 2) que recoge los resultados por finalidad para el total de los 10 museos analizados.

Este resultado está muy alineado con las conclusiones del estudio realizado por Capriotti y Losada_Diaz(2015) en su comparativa de actividad en Facebook de los museos más visitados, a nivel nacional e internacional, donde concluía que la actividad habitual ofrecía una clara orientación a difundir las actividades cotidianas del museo.

Gráfico 2. Finalidad principal de los mensajes para el conjunto de la muestra

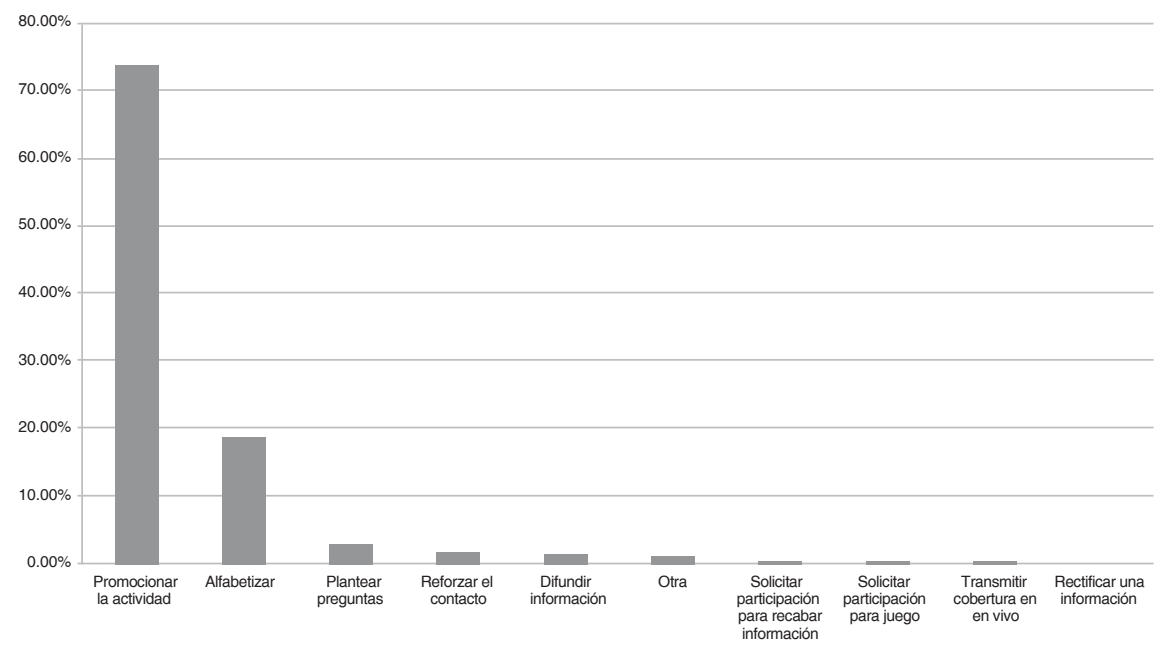

Fuente: Elaboración propia

\subsection{Los museos catalanes son los que hacen un uso más promocional de este servicio}

Los resultados también revelan que, aunque la promoción es bastante habitual para el conjunto de la muestra, los museos que más emplean Facebook con este propósito promocional son los 3 catalanes. El Museo Nacional de Arte de Cataluña recurre a esta finalidad en el 94,3\% de las actualizaciones que publica durante el periodo objeto de estudio. El 
Museo Picasso de Barcelona lo hace en un $91,9 \%$ y el MACBA en un $88,3 \%$. En el lado contrario, el museo que menos emplea este canal para promocionar su actividad es el del Prado que dedica a esta finalidad el 38,8\% de sus mensajes. Los porcentajes para cada uno de los museos quedan expresados en el gráfico 3 .

En ocasiones esta promoción se completa incluyendo la propia página web. Encontramos este tipo de enlaces en casi el 50\% del total de la muestra. Dicho de otra forma: de cada dos mensajes, uno enlaza a la página web del museo. Parece por tanto bastante habi- tual que los museos analizados empleen Facebook como un modo adicional de dirigir tráfico a sus propios sitios. No obstante, en el análisis por museos vemos que no se trata de una práctica homogénea sino que presenta bastante variedad entre los museos analizados. Los que más enlazan a sus propias páginas web son el Museo de Bellas Artes de Bilbao, el Reina Sofía y el MACBA, con porcentajes de $85 \%, 77 \%$ y $72 \%$, respectivamente. Los que menos el Prado, el CAC de Málaga y el Guggenheim de Bilbao que enlazan a sus páginas web en un $19 \%, 17 \%$ y $14 \%$ de sus muestras, respectivamente.

Gráfico 3. Uso promocional de Facebook por museo analizado

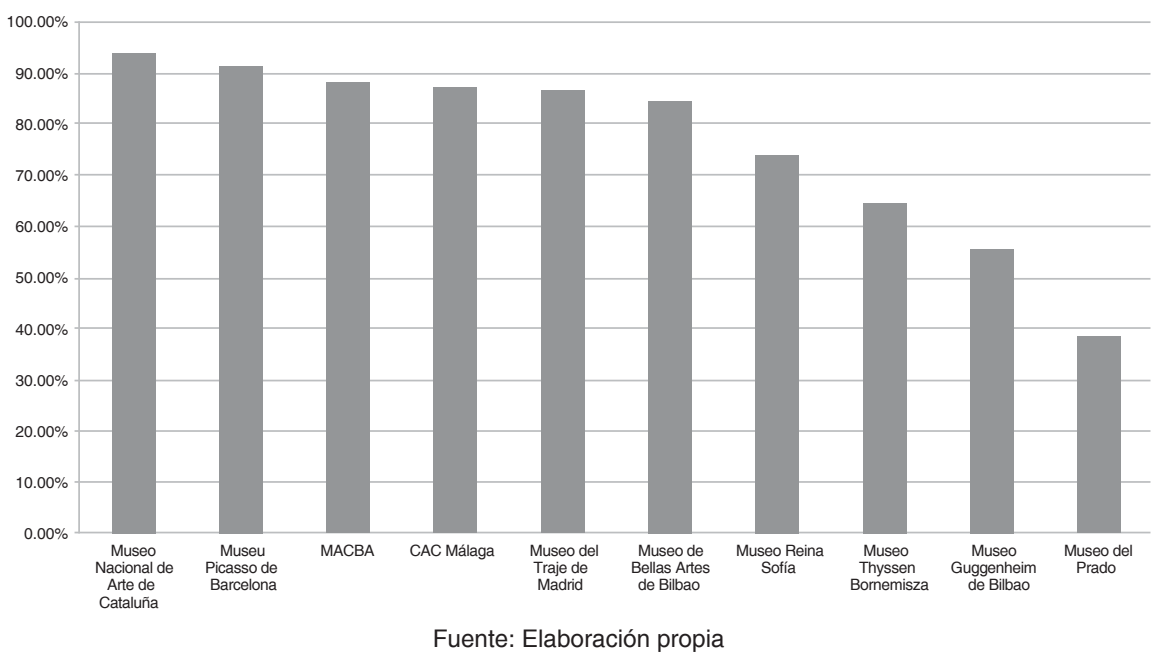

Enlazar a la aplicación móvil del museo como parte de la estrategia promocional resulta una fórmula mucho menos habitual. Sólo la encontramos en 5 de las 2.336 actualizaciones analizadas. Estas publicaciones correspon- den tan sólo a 3 museos. En concreto, el Museo Thyssen Bornemisza publica dos mensajes con enlace a su $a p p$, el MACBA otras dos y el Museo Nacional de Arte de Cataluña la publicación restante. 


\subsection{El Museo del Prado es el que más emplea Facebook con un propósito al- fabetizador}

Tras la promoción, la siguiente finalidad que registra una mayor frecuencia es la relativa a alfabetizar en relación con una obra, un artista o una colección, presentándola y dándola a conocer. Encontramos un ejemplo de esta finalidad en la gráfica 1:

Figura 1. Mensaje orientado a alfabetizar a los usuarios respecto al arte
$\underset{\substack{\text { RRADO } \\(000}}{200}$
Museo Nacional del Prado agregó 4 fotos nuevas.
7 de noviembre a las $17: 04 \cdot C$

\section{ELEMENTOS DE OTRO TIEMPO: GUARDAINFANTE}
La imagen femenina del siglo XVII está ligada a un elemento singular: el guardainfante. Es un armazón interior, colocado alrededor de la cintura, que servía para ahuecar las faldas. Procedente de la corte francesa, la denominación de guardainfante se debe a que sirvió para ocultar los embarazos y aplanar el vientre.

Este armazón se realizaba con aros de madera, alambre o hierro que se unian mediante cintas o cuerdas. Con el fin de moldear la figura femenina, enfatizando las caderas, la parte superior se completaba con mimbre, almohadillas, esparto, ballenas o paja. Además del armazón, la indumentaria se componía de toda una sucesión de capas: las enaguas (de dos a tres), sobre ellas, el guardainfante, sobre éste, la pollera, falda interior de colores vistosos y ricos tejidos, y cubriendo la pollera, la basquiña o falda exterior. Debido al gran tamaño del guardainfante, la tela quedaba muy estirada y lucia espléndida y voluminosa, contrastando con el cuerpo, muy entallado, que aplastaba el pecho.

Inicialmente, la forma del guardainfante era redondeada, una imagen muy conocida, puesto que coincide con la vestimenta de la infanta Margarita, doña Maria Agustina Sarmiento y doña Isabel de Velasco en "Las meninas" de Velázquez. Posteriormente, se fue estrechando y alargando hacia los lados, tal y como se observa en el retrato de la infanta Margarita de Austria, realizado por Martínez del Mazo hacia 1665.

Según señalaba Alonso de Carranza en 1636:

"Lo ancho y pomposo del traje que comienza con gran desproporción desde la cintura les presta comodidad para andar embarazadas de nueve y diez meses, sin que desto puedan ser notadas, principalmente las que usan guardainfantes que de aqui dicen tomo el nombre esta diabólica invención, que junto con ella nos vino de Francia, donde es tradición que habiendo hecho preñada fuera de matrimonio una doncella de gran porte dio principio a este traje para encubrir su miseria y que con esto le dio el nombre de guardainfante, por el efecto no podía cosa tan vil tener más alto precio, ni más infame nombre para ser denotada: convidando juntamente a libertad y sensual lascivia".

El guardainfante desapareció en la segunda mitad del siglo XVIl y fue reemplazado por el tontillo, pero se ha convertido en un elemento esencial de la iconografia velazqueña hasta nuestros dias. De hecho, Sorolla se sirvió de esta moda para vestir a Maria Guerrero en el retrato que pintó de esta actriz como La dama boba, realizando su particular homenaje a Velázquez. 
No obstante, como adelantábamos, la frecuencia con la que los museos seleccionados recurren a Facebook para este propósito es bastante menor, ya que sólo la encontramos en el 18,8\% del total de la muestra frente al 73,8\% de los mensajes que se orientan a promocionar la actividad. El museo que más utiliza Facebook para alfabetizar es el Prado, algo que hace en un 57,6\% de sus publicaciones. Le sigue a dis- tancia el Museo Thyssen Bornemisza en un 32,7\% y el Museo Reina Sofía en un $24,6 \%{ }^{3}$. Por el contrario, los museos que menos utilizan este canal para alfabetizar son los catalanes Museo Picasso con un 1,4\% de sus publicaciones, el MACBA con un 2,2\% y el Museo Nacional de Arte de Cataluña, con un 3,8\%. La distribución de esta categoría queda reflejada en la siguiente tabla.

Tabla 4. Porcentaje de mensajes dedicados a alfabetizar como primera finalidad

\begin{tabular}{|l|c|}
\hline Museos & Porcentaje sobre el total de su muestra \\
\hline Museo del Prado & $57,6 \%$ \\
\hline Museo Thyssen Bornemisza & $32,7 \%$ \\
\hline Museo Reina Sofía & $24,6 \%$ \\
\hline Museo de Bellas Artes de Bilbao & $13,6 \%$ \\
\hline Museo Guggenheim de Bilbao & $11,7 \%$ \\
\hline CAC Málaga & $8,9 \%$ \\
\hline Museo del Traje de Madrid & $8,0 \%$ \\
\hline Museo Nacional de Arte de Cataluña & $3,8 \%$ \\
\hline MACBA & $2,2 \%$ \\
\hline Museu Picasso de Barcelona & $1,4 \%$ \\
\hline
\end{tabular}

Fuente: Elaboración propia

4.5. Salvo excepciones, los museos analizados apenas interactúan con sus seguidores

A la hora de analizar si los museos aprovechan la bidireccionalidad que les ofrece Facebook, nos fijamos primero en el número de interacciones o respuestas a los comentarios que los seguidores dejan en sus mensajes. Encontramos un ejemplo en el siguiente post:

3 Estos tres museos madrileños, apenas separados en unos cientos de metros, conforman la que se denomina la "Milla del Arte de Madrid". 
Figura 2. Ejemplo de publicación en la que un museo interactúa con un usuario

\section{0 veces compartido}

Escribe un comentario...

Fernando González Quenos dias amigos de El Prado. No se si estoy equivocado, pero me extran̉ó un poco la fecha e investigué en Internet. ¿Claudio Coello no nació el 2 de marzo? (Y por eso colocan su obra hoy) me parece que tienen un pequeño error ahi.

Saludos desde venezuela y muchísimas gracias por estas joyas que nos regalan a diario.

Me gusta - Responder - Compartir - 1 - Ayer a las 13:13

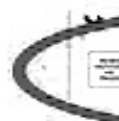

Museo Nacional del Prado 2 Hola Fernando, convencionalmente, cuando se desconoce la fer a exacta de nacimiento, se suele utilizar

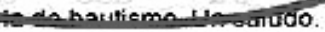

Me gusta - Responder - Compartir $01.6 \mathrm{~h}$

Augusto Olalde Hasta cuando San Tal o San Cual ? Hasta cuando virgenes, santos y arcángeles? No hay otras cosas en el Prado? Me gusta - Responder - Compartir-Ayer a las 12:17

\section{Fuente: Facebook}

En total registramos 578 publicaciones con interacciones, lo cual supone un $24,7 \%$ sobre el conjunto de la muestra. No obstante, este dato esconde una realidad que es muy diferente según consideremos un museo $\mathrm{u}$ otro. El Guggenheim de Bilbao es el que ofrece un mayor nivel de interacción con sus usuarios, en 228 interacciones de sus 324 mensajes, lo que representa una comunicación bidireccional en el $70 \%$ de su muestra. El Museo Thyssen Bornemisza ocupa el segundo puesto, con 114 interacciones sobre un volu- men de 251 publicaciones, lo que supone un $45 \%$. En tercer puesto, el Museo del Traje de Madrid interactúa con sus seguidores en el $35 \%$ de sus mensajes.

A la cola, el Museo Reina Sofía, que sólo interactúa en 8 de los 404 mensajes que publica durante el periodo objeto de estudio. Aunque este museo ocupa el primer puesto en cuanto al volumen de publicaciones aparece en último lugar con respecto al nivel de interacción. Los museos Picasso de Barcelona y MACBA apenas interactúan tampoco con sus seguidores. 
Gráfico 4. Porcentaje de interacciones por museo analizado

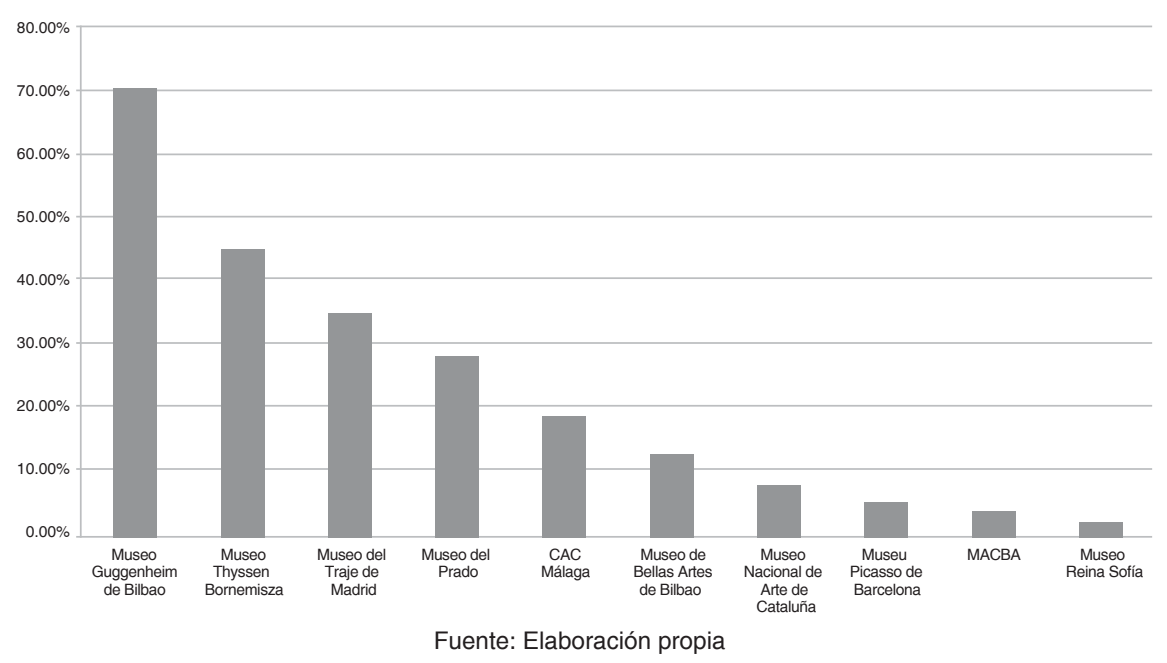

4.6. Los museos analizados desaprovechan el potencial de Facebook para reforzar el contacto con sus seguidores

En general, los museos estudiados no utilizan este canal para reforzar el contacto con sus fans. De las 2.336 publicaciones estudiadas, tan sólo 39 tienen ésta como finalidad principal, lo que supone un $1,7 \%$ sobre el total de la muestra. También en este punto vuelve a destacar el Museo Guggenheim de Bilbao, si bien la frecuencia con la que aprovecha Facebook para este propósito continúa siendo minoritaria y no supera el $9 \%$ de su muestra.

Los datos mejoran algo si atendemos al refuerzo del contacto como segunda finalidad. En concreto, esta función fáctica aparece como segunda intencionalidad en 60 de los 2.336 mensajes analizados lo que supone un $2,6 \%$ sobre el conjunto de la muestra.

Otro de los modos con los que los museos pueden crear comunidad es solicitar la participación de sus seguidores para recabar información u opinión o para pedirles que participen en un juego o concurso. Sin embargo, los resultados revelan que sólo 4 de las 2.336 publicaciones se orientaron a recabar información u opinión y únicamente otras 4 para solicitar su participación en un juego o concurso. 
Gráfico 5. Porcentaje de mensajes que refuerzan el contacto por museo analizado

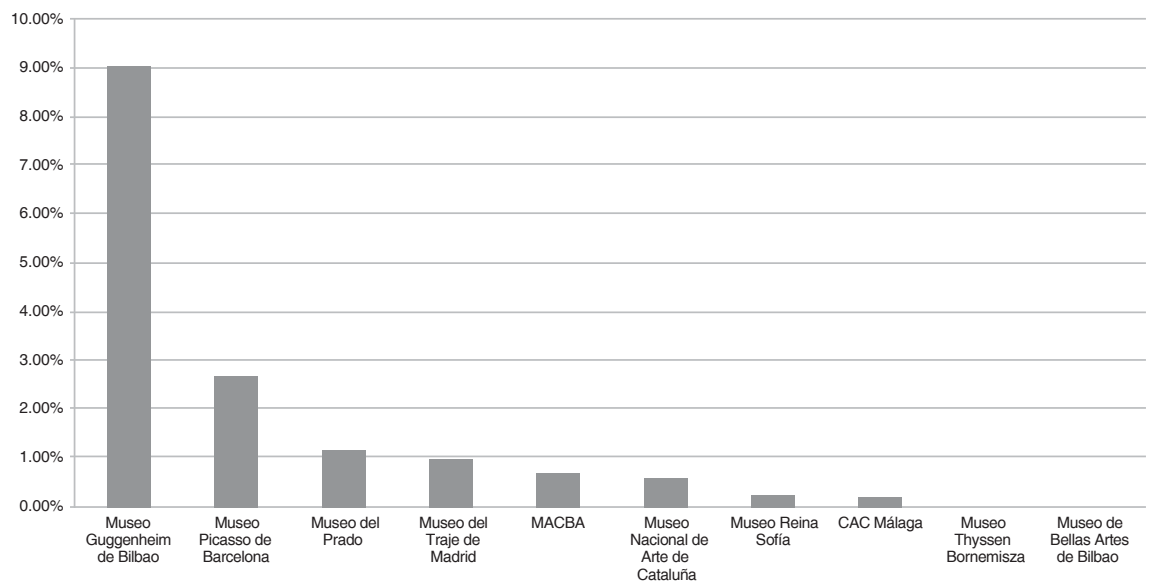

Fuente: Elaboración propia

Gráfico 6. Porcentaje de mensajes con mención por museo analizado

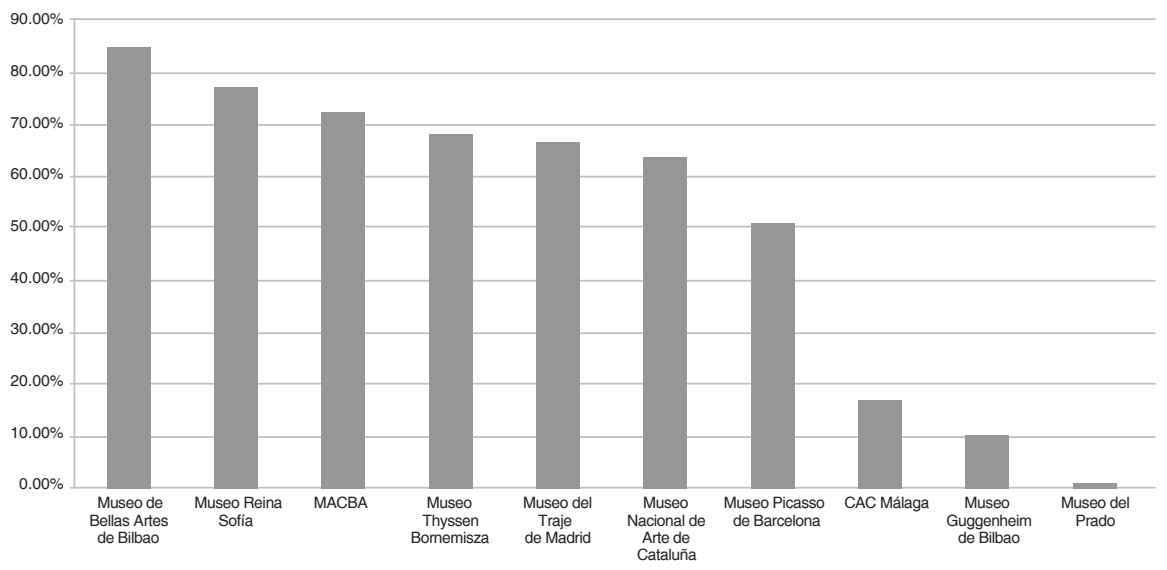

Fuente: Elaboración propia 


\subsection{Distribución heterogénea en cuan- to al número de menciones}

En términos de creación de comunidad, algo más positivo resulta el dato de la frecuencia con la que los museos mencionan otras cuentas bien sean éstas de otros museos, fundaciones, exposiciones, medios de comunicación, instituciones culturales, etc. En efecto, 1.101 del total de 2.336 mensajes menciona otras cuentas, algo que supone un $47,1 \%$ sobre el conjunto de la muestra. No obstante, una lectura más detallada de este porcentaje nos permite advertir que no se trata de una práctica homogénea en todos los museos. Resulta bastante habitual en el Museo de Bellas Artes de Bilbao y en el Reina Sofía, con porcentajes de $84,9 \%$ y el $77,2 \%$, respectivamente. Es, sin embargo, mucho menos habitual en el CAC de Málaga, Guggenheim de Bilbao y en el Museo del Prado, tal como apreciamos en el gráfico 6.

\subsection{Los museos analizados apenas aprovechan Facebook para enlazar a otras redes sociales}

A pesar de que enlazar a otras redes sociales en las que el museo pueda tener un perfil ofrece nuevas posibilidades de seguir construyendo comunidad en esos otros espacios, apenas observamos este tipo de enlaces. Sólo 66 de las 2.336 actualizaciones enlazan a otras redes sociales, apenas un 2,8\% sobre el conjunto de la muestra. En los casos en los que se enlaza otras redes, resulta más habitual hacerlo a Youtube, en el 1,9\% sobre el total de la muestra, y a Vimeo, en un 0,3\%. Conviene recordar que estos dos servicios tienen un carácter más promocional que orientado a la generación de engagement y a la creación de comunidad. Los datos para el conjunto de la muestra quedan recogidos en la siguiente tabla:

Tabla 5. Publicaciones con enlace a redes sociales sobre el total de la muestra

\begin{tabular}{|l|c|c|}
\hline Redes sociales & Número de publicaciones & $\%$ sobre el total \\
\hline Youtube & 46 & $1,97 \%$ \\
\hline Vimeo & 8 & $0,34 \%$ \\
\hline Instagram & 5 & $0,21 \%$ \\
\hline Twitter & 3 & $0,13 \%$ \\
\hline Storify & 2 & $0,09 \%$ \\
\hline Pinterest & 1 & $0,04 \%$ \\
\hline Google + & 1 & $0,04 \%$ \\
\hline
\end{tabular}

Fuente: Elaboración propia 
4.9. El uso de fotos resulta muy habitual

Como sospechábamos en la formulación de la tercera hipótesis, resulta muy común que los museos publiquen sus mensajes utilizando fotografías. De las 2.336 publicaciones estudiadas, 2.160 utilizan este recurso, lo que supone un 92,5\% de la muestra. Desde una perspectiva más concreta, lo más común es que los museos incluyan en sus posts una sola foto, algo que ocurre en el $88,3 \%$ de las publicaciones con imágenes.

Tabla 6. Frecuencia de uso de fotos y porcentaje el conjunto de la muestra

\begin{tabular}{|c|c|c|}
\hline $\begin{array}{l}\text { Número de fotos } \\
\text { por publicación }\end{array}$ & $\begin{array}{c}\text { Número de } \\
\text { publicaciones }\end{array}$ & $\begin{array}{l}\% \text { sobre el total } \\
\text { de la muestra }\end{array}$ \\
\hline 1 & 1.900 & $81,3 \%$ \\
\hline 2 & 103 & $4,4 \%$ \\
\hline 3 & 86 & $3,7 \%$ \\
\hline 4 & 34 & $1,4 \%$ \\
\hline 5 & 15 & $0,6 \%$ \\
\hline 6 & 6 & $0,2 \%$ \\
\hline 7 & 3 & $0,1 \%$ \\
\hline 8 & 2 & $0,1 \%$ \\
\hline 9 & 1 & $0,0 \%$ \\
\hline 10 & 1 & $0,0 \%$ \\
\hline 12 & 2 & $0,1 \%$ \\
\hline 13 & 1 & $0,0 \%$ \\
\hline 15 & 1 & $0,0 \%$ \\
\hline 17 & 1 & $0,0 \%$ \\
\hline 23 & 1 & $0,0 \%$ \\
\hline 28 & 1 & $0,0 \%$ \\
\hline 29 & 1 & $0,0 \%$ \\
\hline 100 & 1 & $0,0 \%$ \\
\hline Sí hay & 2.160 & $92,5 \%$ \\
\hline No hay fotos & 176 & $7,5 \%$ \\
\hline
\end{tabular}

Fuente: Elaboración propia

4.10. Empleo menor de audios, vídeos, emoticonos o transmisiones en vivo

Bastante menos frecuentes resultan los enlaces a audio, que encontramos sólo en 15 de las publicaciones analizadas, apenas un $0,6 \%$ sobre la muestra. Los museos que utilizan este recurso son el Museo Reina Sofía, que, durante el periodo objeto de estudio publica 5 posts con un audio, y el MACBA, que publica 9 mensajes con un audio y uno con 3 audios. En el siguiente ejemplo, el Museo Reina Sofía publica un mensaje con un audio, en este caso incrustado en su página web: 
Figura 3. Ejemplo de post que incluye audio

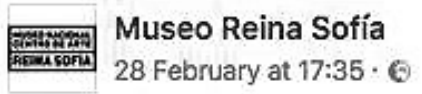

Ya puedes escuchar el encuentro entre el coreógrafo Boris Charmatz y João Fernandes, subdirector artístico del Museo http://www.museoreinasofia.es/mult.../encuentro-boris-charmatz

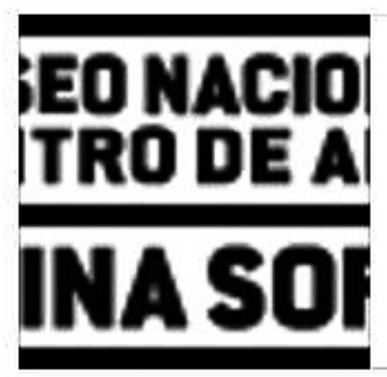

\section{Encuentro con Boris Charmatz | Museo Nacional Centro de Arte Reina Sofía}

Encuentro con Boris Charmatz. Sitio web del Museo Reina Sofía. Información y programación de...

MUSEOREINASOFIA.ES

Like

Comment

\section{Share}

Fuente: Facebook

Pese a lo que cabría esperar, el uso del vídeo tampoco resulta muy habitual. Los encontramos sólo en 147 de las
2.336 publicaciones, un 6,3\% del total. La distribución de vídeos por museo queda expresada en la siguiente tabla:

Tabla 7. Frecuencia y porcentaje de publicaciones con vídeo por museo analizado

\begin{tabular}{|l|c|c|}
\hline Museos & $\begin{array}{c}\text { Número de } \\
\text { publicaciones }\end{array}$ & $\begin{array}{c}\% \text { sobre el total } \\
\text { de su muestra }\end{array}$ \\
\hline Museo del Prado & 42 & $9,3 \%$ \\
\hline Museo de Bellas Artes de Bilbao & 12 & $7,0 \%$ \\
\hline MACBA & 11 & $6,7 \%$ \\
\hline Museo Reina Sofía & 28 & $6,9 \%$ \\
\hline Museo Guggenheim de Bilbao & 14 & $5,3 \%$ \\
\hline CAC Málaga & 17 & $5,3 \%$ \\
\hline Museo Thyssen Bornemisza & 13 & $5,2 \%$ \\
\hline Museo Nacional de Arte de Cataluña & 4 & $4,0 \%$ \\
\hline Museo Picasso de Barcelona & 4 & $2,9 \%$ \\
\hline Museo del Traje de Madrid & 2 & $2,7 \%$ \\
\hline
\end{tabular}


Finalmente, en cuanto a la posibilidad de transmitir en vivo, los resultados reflejan que sólo 3 de las 2.336 publicaciones recurren a esta práctica. Estas 3 actualizaciones corresponden siempre al Museo del Prado. Durante el periodo objeto de estudio, esta posibilidad no resulta nada habitual entre los museos estudiados, pese a que podría ofrecer muchas posibilidades tal como podemos apreciar en la siguiente captura:

Figura 4. Mensaje con retransmisión en directo a través de Facebook Live

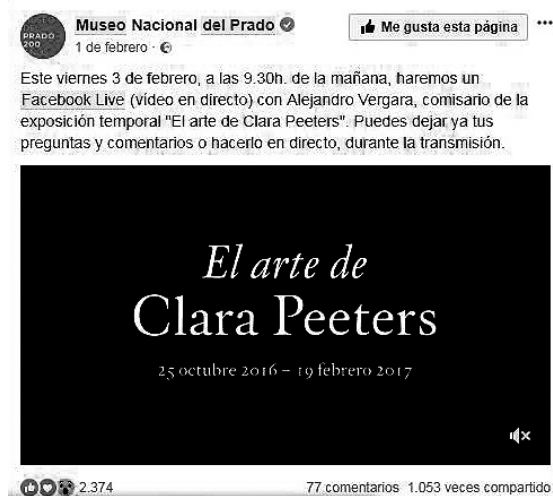

Fuente: Facebook

\section{Conclusiones}

Los resultados certifican el cumplimiento de nuestras 3 hipótesis de partida.

PRIMERA CONCLUSIÓN: En efecto, los museos españoles han normalizado el empleo de Facebook, canal que utilizan sobre todo para visibilizar $y$ promocionar su actividad. El uso alfabetizador de la herramienta resulta, sin embargo, bastante menos habitual de lo que hubiésemos esperado.

SEGUNDA CONCLUSION: Se cumple también lo que planteábamos en nuestra segunda hipótesis sobre el escaso aprovechamiento que los museos españoles hacen del potencial que ofrece Facebook para generar comuni- dad. Las únicas excepciones vendrían del Museo Guggenheim de Bilbao que interactúa en el $70 \%$ de sus publicaciones y, en menor medida, del Museo Thyssen Bornemisza y Museo del Traje de Madrid, con ratios de interacción del $45 \%$ y $35 \%$, respectivamente.

TERCERA CONCLUSIÓN: Asimismo, comprobamos también que los museos analizados recurren de manera prioritaria a las fotos y desaprovechan otras posibilidades de enriquecer sus actualizaciones a través de elementos multimedia como los audios, vídeos, las transmisiones en vivo y el empleo de emoticonos, si bien esto último se entiende por el tono relativamente formal que suelen emplear los museos en sus mensajes. 
CONCLUSIÓN FINAL: Por lo demás, el análisis de la comunicación de los museos españoles en Facebook es ambivalente. Entre los aspectos más positivos constatamos que los museos ciertamente parecen darse cuenta del potencial que ofrece Facebook para su comunicación y optan por aprovechar bien este canal, también por el alto índice de penetración que tiene en España (según el Estudio Anual de Redes Sociales 2017 de $\mathrm{IAB}^{4}$, Facebook es la red social más visitada, usada y conocida en este país). También son positivos los ratios de interacción de algunos museos -el Guggenheim de Bilbao (70\%), Thyssen Bornemisza (45\%) y Museo del Traje de Madrid (35\%)-, el porcentaje de mención para el conjunto de la muestra $(47,1 \%)$ y las frecuencias con las que el Museo de Bellas Artes de Bilbao (84,9\%) y el Reina Sofía $(77,2 \%)$ mencionan otras cuentas. Además, el uso de fotos resulta muy habitual $(92,5 \%)$ y se distribuye de modo homogéneo a lo largo de toda la muestra, algo que tal vez se explique por la carga fuertemente visual del museo como institución.

En el lado negativo, destacamos la poca variedad que se hace del uso de esta herramienta ya que casi todos los mensa- jes se orientan de manera invariable a promocionar la actividad $y$, en mucha menor medida, a alfabetizar. Son muy pocas las actualizaciones que tienen otra finalidad distinta de estas dos. Llama también la atención el abuso de la finalidad promocional en el empleo de esta red, especialmente en el Museo Nacional de Arte de Cataluña, Museo Picasso de Barcelona y en el MACBA. Son también muy escasas las ocasiones en las que los museos interactúan con sus seguidores, refuerzan el contacto con ellos o solicitan su participación para recabar información u opinión o para pedirles que participen en un juego o concurso. Análogamente los museos analizados desaprovechan la posibilidad de enlazar a otras redes sociales donde puedan tener un perfil como un modo complementario de seguir construyendo comunidad. Los museos tampoco aprovechan elementos multimedia claramente visuales como el vídeo o la posibilidad de llevar a cabo coberturas en vivo cuando constituyen posibilidades reales y concretas de enriquecer su comunicación. Estos aspectos serían los más urgentes de corregir para aprovechar mejor Facebook en el logro de un museo más social, abierto y participativo.

\section{Bibliografía}

Bardin, L. (1991): Análisis de contenido. Akal: Madrid

Berelson, B. (1952). Content Analysis in Comunication Research. Glencoe: Free Press.

Cano, L., Vázquez, J.A. y Celaya, J. (2015). Focus. Museos y nuevas tecnologías. En: Celaya, J. (dir). Anuario AC/E de cultura digital 2015. Modelos de negocio culturales en Internet. (pp. 217-

4 Internet Advertising Bureau España, IAB, Estudio Anual de Redes Sociales 2017, disponible en http://iabspain.es/ wp-content/uploads/iab_estudioredessociales_2017_vreducida.pdf, fecha de consulta: 24 de febrero de 2018. 
312). Madrid: Acción Cultural Española. Recuperado de: http://www.dosdoce.com/upload/ ficheros/noticias/201503/anuario_ace_de_cultura_digital_2015.pdf

Capriotti, P., \& Losada-Diaz, J. C. (Julio de 2015). La comunicación de los museos de arte en Facebook: comparación entre las principales instituciones internacionales y españolas. SCIELO, 18(3).

Castilla, P. (2012). Entornos museísticos. Nuevas tecnologías expositivas. Telos, 90, 87-96.

Cordón, D., \& González González, D. (2016). Museos y Comunicación: Los nuevos medios como herramienta de diálogo y sociabilidad de la institución. Fonsesa. Journal of Comunication, 149-165.

Desvallèes, A. y Mairesse, F. (2010). Conceptos clave de museología. Recuperado de: http://icom. museum/fileadmin/user_upload/pdf/Key_Concepts_of_Museology/Museologie_Espagnol_BD.pdf

De Varine-Bohan, H. (1973). Rôle du musée dans l'Amérique latine d'aujourd'hui. Table ronde organisée par l'Unesco, Santiago du Chili, 1972. Museum, XXV, 3, 129-133. Recuperado de: http://unesdoc.unesco.org/images/0012/001273/127362fo.pdf

De Varine-Bohan, H. (1978). L'écomusée. Gazette, 11, 2, 29-40.

De Varine-Bohan, H. (1979). Los museos en el mundo. Madrid: Salvat.

De Varine-Bohan, H. (1989). La muséologie selon Georges Henri Rivière. Paris: Dunod.

De Varine-Bohan, H. (1993). La participación de la población. En: Rivière, G.H. (ed.). La Museología. Textos y testimonios. Madrid: Akal.

Gómez Vílchez, S. (2010). Estadística: museos y redes 2010. Recuperado de: https://mediamusea.files.wordpress.com/2010/12/museosredes.pdf

Gómez Vílchez, S. (2012a). Evaluación de preferencia y participación. Museos españoles y redes sociales. Telos, 90, 79-86. Recuperado de: https:/telos.fundaciontelefonica.com/ seccion $=1268 \&$ idioma $=$ es_ES\&id $=2012013116530001 \&$ activo $=6$.do

Gómez Vílchez, S. (2012b). Museos y redes. Recuperado de: https://mediamusea.files.wordpress.com/2010/12/museosredes.pdf

Gómez Vílchez, S. (2012c). Las primeras apps móviles de museos. Recuperado de: https:// mediamusea.com/2012/01/25/primeras-apps-museos/

Keene, S. (2004). El futuro del museo en la era digital. Noticias del ICOM, 3, 4-5.

Recuperado de: http://icom.museum/fileadmin/user_upload/pdf/ICOM_News/2004-3/ SPA/p4-5_2004-3.pdf

Lavado, P.J. (2011). Museos para todos. Accesibles, inclusivos y multiculturales. Revista Digital del Comité Español de ICOM, 2 9-18. Recuperado de: http://www.icom-ce.org/recursos/ ICOM_CE_Digital/02/ICOMCEDigital02.pdf

Llerena, S. (2016). La comunicación de los museos españoles en Twitter: análisis de la situación y establecimiento de buenas prácticas [Tesis Doctoral inédita]. Universidad Carlos III de Madrid. Recuperado de: https://e-archivo.uc3m.es/bitstream/handle/10016/22291/ llerena_museos_tesis_2015.pdf?sequence $=1$

Mas, J.M. (2018). "La comunicación de los museos españoles en Facebook: análisis de la situación y establecimiento de buenas prácticas". Tesis Doctoral. Universidad Carlos III de Madrid (España). 
Mateos, S. (2012). ARTvertisers. Arte y publicidad en las vanguardias históricas. Questiones Publicitarias(nำ17).

Miranda, G. (2012). Hacia un nuevo modelo de museo: experiencia, participación y análisis de audiencias. ICOM Digital, 5. Recuperado de: https://murosyredes.wordpress. com/2013/07/27/03-museoparticipativo/

Moreno, M. (2014). El gran libro del community manager: técnicas y herramientas para sacarle partido a las redes sociales y triunfar en social media. Madrid: Gestión 2000.

Moreno, M. (2015). Cómo triunfar en las redes sociales: consejos prácticos y técnicas para conseguir todo lo que te propongas en Internet y sacarle más partido a tus redes Facebook, Twitter, Instagram, LinkedIn.... Madrid: Gestión 2000.

Moreno, M. (2018). La enciclopedia del community manager. Madrid: Deusto.

Viñaras, M., \& Caerols, R. (2016). \#5Museos: un caso de éxito sobre la oportunidad de las redes sociales para generar engagement. Revista Internacional de Relaciones Públicas, 169-190.

Wimmer, R.D. y Dominick, J.R. (2011). Mass Media Research: an Introduction. Boston: Wadsworth. $9^{\text {th }}$ edition. 